\title{
Pemodelan Gerak Partikel Butiran pada Proses Granulasi pada Pembuatan Pupuk Granul
}

\author{
Yopy Mardiansyah ${ }^{1^{\star}}$, Delia Meldra ${ }^{2}$, dan Yulia ${ }^{3}$ \\ ${ }^{1}$ Institut Teknologi Batam, Teknik Industri, Batam \\ ${ }^{2}$ Universitas Ibnu Sina, Teknik Industri, Batam \\ ${ }^{3}$ Institut Teknologi Bandung, Fisika, Bandung \\ *E-mail: yopi@iteba.ac.id
}

\begin{abstract}
Abstrak
Salah satu upaya yang dapat ditempuh dalam mengembalikan kemampuan tanah dalam menyerap unsur hara adalah dengan mengganti pupuk anorganik dengan pupuk organik. Pupuk organik dapat mengembalikan kandungan organik di dalam tanah. pemberian pupuk organik dalam bentuk granul dapat meningkatkan pertumbuhan dan produksi tanaman. Pada proses granulasi, adonan pupuk mengalami pembesaran karena partikelpartikel halus saling menempel membentuk butiran yang lebih besar. Perlu dilakukan pengadukan agar butiran yang dihasilkan tidak melebihi ukuran yang diinginkan. Jika waktu pengadukan tidak tepat, maka akan terjadi penggumpalan pada bagian bawah dan dinding-dinding piringan. Tujuan dari penelitian ini yaitu menghasilkan model gerak partikel butiran pada proses granulasi pada proses pembuatan pupuk organik granul. Berdasarkan penelitian yang telah dilakukan dapat disimpulkan bahwa terdapat 5 mode gerak partikel butiran pada wadah silinder tipis yang bergerak rotasi dengan variasi kecepatan sudut dan jumlah partikel yang dapat diamati dengan rentang nilai kecepatan 15 rpm-120 rpm dan jumlah partikel 50-200 butir. Gerak partikel butiran pupuk granul saat proses granulasi termasuk dalam mode gerak cateracting. Untuk memprediksi mode gerak partikel butiran dapat ditentukan dengan batas nilai Froude Number (Fr).
\end{abstract}

Kata kunci: Granul, Pupuk Organik, Tanah, Granulasi

\begin{abstract}
One of the efforts that can be taken to restore the soil's ability to absorb nutrients is by replacing inorganic fertilizers with organic fertilizers. Organic fertilizers can restore the organic content in the soil. Organic fertilizer in the form of granules can increase plant growth and production. In the granulation process, the fertilizer mixture is enlarged because the fine particles stick together to form larger granules. It is necessary to stir so that the resulting granules do not exceed the desired size. If the mixing time is not right, there will be lumps on the bottom and walls of the dish. The purpose of this research is to produce a model of granular particle motion in the granulation process in the process of making granule organic fertilizer. Based on the research that has been done, it can be concluded that there are 5 modes of motion of the granular particles in a thin cylindrical container that moves rotation with variations in angular velocity and the number of particles that can be observed with a range of velocity values of $15 \mathrm{rpm}-120 \mathrm{rpm}$ and the number of particles 50-200 grains. The motion of the fertilizer granule particles during the granulation process is included in the catarecting motion mode. To predict the motion mode of the particle grains can be determined by the limit value of the Froude Number (Fr).
\end{abstract}

Keywords: Granul, Organic Fertilizer, Soil, Granulation 


\section{Pendahuluan}

Penggunaan pupuk untuk menjaga kesuburan tanah saat ini masih menjadi pilihan utama bagi petani di Indonesia. Padahal penggunaan pupuk jenis anorganik dengan takaran yang tidak jelas dan secara terus menerus akan menimbulkan efek menurunkan kualitas tanah dalam penyerapan unsur hara. Jika kemampuan tanah dalam menyerap unsur hara sudah berkurang, maka efektivitas dan efisiensi penggunaan pupuk anorganik pun akan menurun.

Salah satu upaya yang dapat ditempuh dalam mengembalikan kemampuan tanah dalam menyerap unsur hara adalah dengan mengganti pupuk anorganik dengan pupuk organik. Pupuk organik dapat mengembalikan kandungan organik di dalam tanah. Pupuk organik yang digunakan ada yang dalam bentuk cair, curah, dan butitan (granul). Berdasarkan hasil penelitian yang telah dilakukan terbukti bahwa pemberian pupuk organik dalam bentuk granul dapat meningkatkan pertumbuhan dan produksi tanaman [1].

Proses pembuatan pupuk granul terdiri dari beberapa tahapan. Salah satunya yaitu proses granulasi. Pada proses granulasi, adonan pupuk mengalami pembesaran karena partikelpartikel halus saling menempel membentuk butiran yang lebih besar. Pupuk yang saling melekat mengalami perputaran akibat gerakan dari piringan tempat adonan. Perlu dilakukan pengadukan agar butiran yang dihasilkan tidak melebihi ukuran yang diinginkan. Jika waktu pengadukan tidak tepat, maka akan terjadi penggumpalan pada bagian bawah dan dinding-dinding piringan. Oleh sebab itu, perlu diketahui model gerak butiran pupuk pada proses granulasi untuk mengetahui waktu pengadukan yang tepat.

Berbagai fenomena muncul dalam material granular ini diantaranya efek kacang Brazil (brazil nuts effect) kebalikan efek kacang brazil (reverse brazil nuts effect), avalansi, segregasi, turbelensi, osilasi balik. Selain fenomena tersebut penelitian juga dilakukan terhadap fenomena pencampuran (mixing) antara material granular sepeti pencampuran material granular dalam rotary drum yang menjadi dasar rotary klin yang digunakan pada industri kimia dan metalurgi. Material butiran banyak dibahas dalam bidang teknologi dan industri karena pemanfaatannya. Salah satunya yaitu pada industri pembuatan pupuk organik granul. Pupuk granul dihasilkan melalui proses granulasi. Pada proses granulasi, adonan pupuk dimasukkan dalam wadah yang digerakkan melingkar pada arah vertikal seperti pada alat rotary klin. Rotary klin berupa silinder panjang yang berputar pada arah vertikal dengan kemiringan tertentu dan kecepatan yang rendah. Terdapat 6 mode gerak partikel butiran ketika bergerak berputar dalam rotary klin yaitu slipping, slumping, rolling, cascading, cataracting, dan centrifuging [2]. Bentuk gerakan partikel butiran dalam rotary klin dapat dilihat pada gambar 1 berikut.

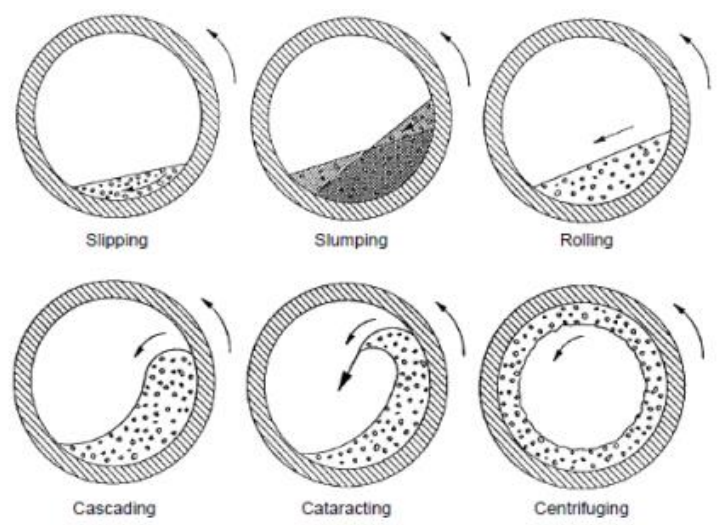

Gambar 1. Mode Gerak Partikel Butiran pada Rotary Klin [3]

1. Slipping : Gerakan meluncur terjadi ketika sejumlah material secara keselurahan tergelincir terhadap dinding rotary klin akibat gaya gesek yang rendah antara dinding dan permukaan material

2. Slumping : Gerakan merosot terjadi ketika sebagian dari sejumlah material pada sisi bagian atas runtuh ke bagian bawah menyebabkan permukaan partikel kembali rata

3. Rotating: Gerakan bergulir terjadi ketika partikel bergilir naik dan turun dengan permukaan butiran yang rata.

4. Cascading: terjadi ketika rotasi tinggi dimana perikel terjun atau memancar ke bawah permukaan yang kosong.

5. Cataracting: terjadi antara keadaan cascading dan centrifuging.

6. Centrifuging: terjadi pada kecepatan kritis dan kecepatan tinggi, semua material berotasi dengan dinding wadah [2].

Perubahan dari cateracting menjadi centrifuging terjadi seiring dengan kenaikan kecepatan rotasi. Partikel pada jalur luar dari gerak cateracting akan mengalami kontak dengan dinding dan bergerak bersama gerak dinding. Mode centrifuging hanya terjadi pada kecepatan rotasi tinggi. Perubahan mode gerak partikel butiran ini dipengaruhi oleh beberapa faktor yaitu kecepatan rotasi wadah, jumlah material yang diisikan dalam wadah, kedalaman partikel, serta 
jenis material. Karakterisasi mode gerak partikel dinyatakan dalam perubahan nilai Forude Number (Fr) yang merupakan perbandingan antara momen inersia dan berat [3].

$$
F_{r}=\frac{\omega^{2} R}{g}
$$

Diameter dalam rotary klin dihitung dengan mengkonversi jumlah partikel menjadi ketinggian yang diukur dari dasar drum seperti diilustrasikan pada gambar 2.5 berikut. Partikel butiran yang tersusun di dalam wadah diukur ketinggiannya dari dasar wadah ke lapisan paling atas dari susunan partikel butiran.

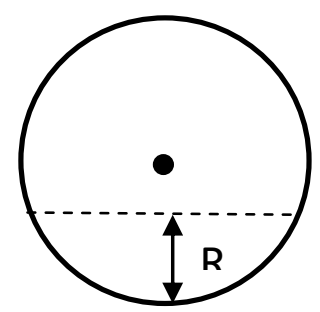

Gambar 2. Definisi jari-jari dalam drum

Penggunaan pupuk organik dalam bentuk granul dapat meningkatkan pertumbuhan dan produksi tanaman [1]. Pupuk organik granul adalah pupuk yang terbuat dari sisa makhluk hidup, kotoran hewan, yang diolah melalui proses pembusukan berbentuk bulatan dengan ukuran diameter $3 \mathrm{~mm}-5 \mathrm{~mm}$ [4]. Hal ini tentunya menjadi landasan penting dalam mengembangkan pembuatan pupuk organik dalam bentuk granul. Secara umum, pupuk organik granul dapat dibuat melalui tahapan pengeringan, penggilingan dan pengayakan, penambahan bahan lain, granulasi, dan pengemasan. Pembentukan butiran pupuk terjadi pada proses granulasi. Proses granulasi atau pembuatan pupuk organik menjadi berbentuk granul merupakan inti dari proses pembuatan POG, yang dilakukan oleh seluruh pabrik POG dengan menggunakan pan granulator.

Pada proses granulasi, adonan pupuk ditempatkan pada wadah yang diputar melingkar pada arah vertikal dengan kemiringan tertentu seperti pada gambar 3 berikut. Pupuk kandang dimasukkan ke dalam piringan granulator. Pengisian pupuk ke dalam piringan granulator dilakukan secara bertahap dengan menggunakan sekop atau menumpahkannya dari dalam karung. Sebaiknya, proses ini dilakukan dalam keadaan piringan berotasi sehingga pupuk dapat langsung bergerak mengikuti perputaran piringan. Selama proses granulasi berlangsung, semprotkan larutan molase $5 \%$. Sebaiknya, penyemprotan dilakukan secara merata dan sedikit demi sedikit agar pupuk tidak menggumpal. Pupuk yang saling merekat akan berputar mengikuti gerakan piringan.

Gerakan perputaran akan menyebabkan terbentuknya butiran butiran granul yang semakin besar. Karena itu, perlu dilakukan pengadukan untuk mencegah terbentuknya butiran berukuran lebih dari $5 \mathrm{~mm}$ yang terakumulasi di bagian bawah piringan. Pengadukan juga berfungsi untuk mencegah terbentuknya kerak pada dinding piringan.

Penelitian ini merupakan penilitian lanjutan dari penelitian yang telah penulis lakukan sebelumnya mengenai "Perancangan dan Pembuatan Alat Pengamatan Gerak Partikel Granular Pseudo-2Dimensi dalam Drum yang Berputar Vertikal'. Pada penelitian ini telah dihasilkan alat yang mampu mengkarakterisasi gerak partikel bed dalam silinder yang berputar pada arah vertikal. Namun pada pelaksanaannya, pemodelan gerak partikel masih sebatas untuk mengkarakterisasi gerak partikel butiran. Prinsip kerja alat ini hampir sama dengan mesin pembuatan pupuk granul pada proses granulasi. Oleh sebab itu, pada penelitian ini alat yang telah dihasilkan digunakan untuk mengkarakterisasi mode gerak partikel butiran pupuk granul dalam bentuk model matematis.

\section{Metode Penelitian}

Berdasarkan penelitian sebelumnya, telah dihasilkan alat yang dapat berfungsi dalam memodelkan gerak partikel granul dengan melakukan uji coba menggunakan butiran-butiran bola bearing dengan diameter $4 \mathrm{~mm}$. Alat yang dihasilkan dalam bentuk pseudo 2 dimensi. Rancangan awal alat dapat dilihat pada gambar 3 berikut.

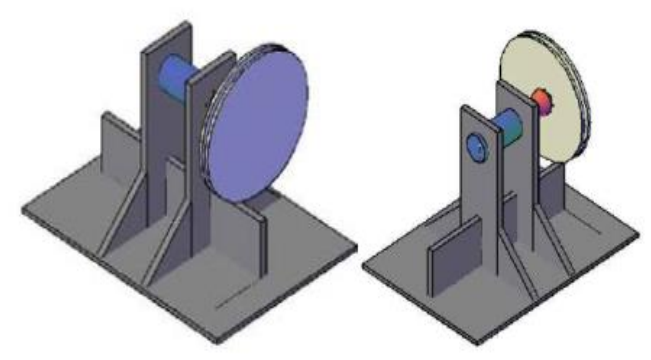

Gambar 3. Rancangan Wadah

Alat ini terdiri dari motor, wadah tempat material, penghubung dari motor ke wadah, dan tiang penyanggah. Motor yang digunakan merupakan motor DC dengan tipe GMX019 DC gear motor 3-12 $\mathrm{V}$ dengan gear ratio 1:120, kecepatan rotasi 8-180 rpm, dan dengan arus 80-180 mA. Motor ini memiliki torsi keluaran 0,8-5,0 kgf.cm. 
Wadah tempat material dan tiang penyanggah terbuat dari akrilik sedangkan penghubung motor ke wadah terbuat dari nilon keras. Diameter dalam wadah $16 \mathrm{~cm}$ dan ketebalan dalam wadah adalah $5 \mathrm{~mm}$ [2].

Sensor kecepatan rotasi yang digunakan berupa optokopler. Untuk memprogram dan mengontrol sensor kecepatan rotasi ini digunakan arduino. Skematik kecepatan rotasi menggunakan optocoppler dapat dilihat pada gambar 3.2. Untuk memprogram dan mengontrol sensor kecepatan rotasi ini digunakan arduino. Arduino berbasis mikrokontroler dan bersifat open source. Arduino dapat digunakan untuk memprogram dan menangani input dari berbagai sensor. Selain itu arduino juga berfungsi sebagai catu daya bagi optocoupler dan LCD. Sebelum menghubungkan ke arduino optocoupler dirangkai dengan dua buah resistor. Hasil pembacaan kecepatan rotasi ditampilkan pada LCD yang juga terhubung dengan arduino. Dengan menggunakan alat yang sama, dilakukan percobaan untuk memodelkan partikel pupuk granul dengan parameter variasi jumlah partikel, serta kecepatan rotasi.

\section{Hasil dan Diskusi}

Berdasarkan analisis sistem pada proses granulasi, dilakukan percobaan untuk mengamati model gerak partikel butiran dengan menggunakan rancangan yang telah ada sebelumnya seperti pada gambar 4 berikut.

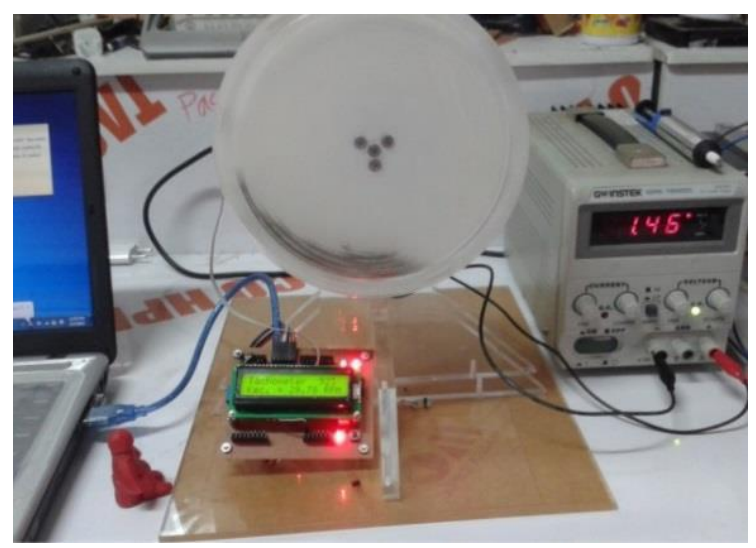

Gambar 4. Alat Pemodelan Proses Granulasi

Percobaan dilakukan dengan dua tahap yaitu, variasi jumlah partikel sebagai representatif massa adonan pupuk organik granul dan variasi kecepatan rotasi wadah. Percobaan dilakukan dengan 3 variasi nilai kecepatan rotasi. Berdasarkan hasil pengamatan, diperoleh beberapa mode gerak partikel.
Tabel 1. Varian Jumlah Partikel ( $\boldsymbol{\omega}=15 \mathrm{rpm})$

\begin{tabular}{ccccc}
\hline No & $\begin{array}{c}\text { Massa } \\
(\mathrm{g})\end{array}$ & $\begin{array}{c}\text { Mode } \\
\text { Gerak }\end{array}$ & $\begin{array}{c}\mathrm{R} \\
(\mathrm{cm})\end{array}$ & $\begin{array}{c}\text { Froude } \\
\text { Number }\left(\times 10^{-4}\right)\end{array}$ \\
\hline 1 & 12,48 & slipping & 1,35 & 0,027034439 \\
2 & 18,71 & slipping & 1,45 & 0,02903699 \\
3 & 24,95 & slipping & 1,55 & 0,031039541 \\
4 & 31,19 & slipping & 1,65 & 0,033042092 \\
5 & 37,43 & slipping & 1,75 & 0,035044643 \\
6 & 43,66 & slipping & 1,95 & 0,039049745 \\
7 & 49,90 & slipping & 2,05 & 0,041052296 \\
8 & 56,14 & slumping & 2,2 & 0,044056122 \\
9 & 62,38 & slumping & 2,4 & 0,048061224 \\
\hline
\end{tabular}

Tabel 2. Varian Jumlah Partikel ( $\omega=60 \mathrm{rpm})$

\begin{tabular}{cclcc}
\hline No & $\begin{array}{c}\text { Massa } \\
(\mathrm{g})\end{array}$ & $\begin{array}{r}\text { Mode } \\
\text { Gerak }\end{array}$ & $\mathrm{R}(\mathrm{cm})$ & $\begin{array}{c}\text { Froude } \\
\text { Number }\left(\times 10^{-4}\right)\end{array}$ \\
\hline 1 & 12,48 & slumping & 1,35 & 0,43255102 \\
2 & 18,71 & slumping & 1,45 & 0,464591837 \\
3 & 24,95 & slumping & 1,55 & 0,496632653 \\
4 & 31,19 & slumping & 1,65 & 0,528673469 \\
5 & 37,43 & slumping & 1,75 & 0,560714286 \\
6 & 43,66 & slumping & 1,95 & 0,624795918 \\
7 & 49,90 & rolling & 2,05 & 0,656836735 \\
8 & 56,14 & rolling & 2,2 & 0,704897959 \\
9 & 62,38 & rolling & 2,4 & 0,768979592 \\
\hline
\end{tabular}

Tabel 3. Variasi jumlah Partikel ( $\omega=125 \mathrm{rpm})$

\begin{tabular}{cclcc}
\hline No & $\begin{array}{c}\text { Massa } \\
(\mathrm{g})\end{array}$ & $\begin{array}{c}\text { Mode } \\
\text { Gerak }\end{array}$ & $\begin{array}{c}\mathrm{R} \\
(\mathrm{cm})\end{array}$ & $\begin{array}{c}\text { Froude } \\
\text { Number }\left(\times 10^{-4}\right)\end{array}$ \\
\hline 1 & 12,48 & rolling & 1,35 & 1,877391582 \\
2 & 18,71 & rolling & 1,45 & 2,016457625 \\
3 & 24,95 & rolling & 1,55 & 2,155523668 \\
4 & 31,19 & rolling & 1,65 & 2,294589711 \\
5 & 37,43 & rolling & 1,75 & 2,433655754 \\
6 & 43,66 & rolling & 1,95 & 2,71178784 \\
7 & 49,90 & cascading & 2,05 & 2,850853883 \\
8 & 56,14 & cascading & 2,2 & 3,059452948 \\
9 & 62,38 & cateracting & 2,4 & 3,337585034 \\
\hline
\end{tabular}

Berdasarkan data variasi jumlah bola bearing yang merepresentasikan massa, diketahui bahwa 
dengan kecepatan putaran wadah yang sama dapat menghasilkan mode gerak yang berbeda. Terdapat perbedaan rentang nilai Froude Number untuk setiap mode gerak.

Percobaan selanjutnya dilakukan dengan variasi kecepatan rotasi wadah silinder vertikal. Untuk jumlah partikel yang sama, dengan merubah nilai kecepatan rotasi wadah, dapat merubah mode gerak partikel butiran. Hal ini dapat lihat pada tabel 4 berikut.

Tabel 4. Variasi jumlah Partikel $(\omega=125 \mathrm{rpm})$

\begin{tabular}{cccc}
\hline No & $\begin{array}{c}\text { Kecepatan } \\
\text { Rotasi }\end{array}$ & Mode gerak & $\begin{array}{c}\text { Froude } \\
\text { Number }\left(\times 10^{-4}\right)\end{array}$ \\
\hline 1. & 15 & Slipping & 0,041052 \\
2. & 25 & Slipping & 0,114034 \\
3. & 30 & Slipping & 0,164209 \\
4. & 37 & Slumping & 0,24978 \\
5. & 48 & Slumping & 0,420376 \\
6. & 60 & Slumping & 0,656837 \\
7. & 73 & Rolling & 0,972301 \\
8. & 88 & Rolling & 1,412929 \\
9. & 105 & Rolling & 2,011563 \\
10 & 120 & Cascading & 2,627347 \\
\hline
\end{tabular}

Melalui percobaan yang telah dilakukan dengan memvariasikan jumlah partikel butiran dan kecepatan rotasi, dapat diamati 5 mode gerak partikel yang berbeda. Klasterisasi mode gerak dapat dilakukan melalui pengamatan serta perhitungan nilai froude number (Fr). Selanjutnya didapat perbandingan antara kecepatan rotasi wadah $(\omega)$ dan ketinggian adonan yang diukur dari dasar wadah dengan nilai froude number (Fr).

\section{Simpulan}

Berdasarkan penelitian yang telah dilakukan dapat disimpulkan bahwa : 1) Terdapat 5 mode gerak partikel butiran pada wadah silinder tipis yang bergerak rotasi dengan variasi kecepatan sudut dan jumlah partikel yang dapat diamati dengan rentang nilai kecepatan $15 \mathrm{rpm}-$ 120 rpm dan jumlah partikel 50-200 butir; 2) Gerak partikel butiran pupuk granul saat proses granulasi termasuk dalam mode gerak cateracting. Untuk memprediksi mode gerak partikel butiran dapat ditentukan dengan batas nilai Froude Number (Fr).

\section{Ucapan Terima Kasih}

Ucapan terimakasih disampaikan kepada Program Studi Teknik Industri Fakultas Teknologi Industri Institut Teknologi Batam yang telah memfasilitasi pelaksanaan penelitian ini.

\section{Daftar Pustaka}

[1]. Tanod, Puyun Fierce MaaS. 2012. "Efektivitas Pupuk Organik Granul Terhadap Pertumbuhan, Produksi Dan Kadar Hara Npk Daun Jagung Manis Pada Latosol Dramaga Puyun Fierce Maas Tanod." Scientitfic Respository Institut Pertanian Bogor. [Online]. Available:

http://repository.ipb.ac.id/handle/123456789/ 61171 [Agustus, 2020].

[2]. Yulia, Yopy Mardiansyah, Dadang Suhendra, and Sparisoma Viridi. "Perancangan dan Pembuatan Alat Pengamatan Gerak Partikel Granular Pseudo-2 Dalam Drum Yang Berputar Vertikal." pp. 109-12.

[3]. Stanev, Rayko, Iliyan Mitov, Eckehard Specht, and Fabian Herz. "Geometrical Characteristics Of The Solid Bed In A Rotary Kiln." Journal of Chemical Technology and Metallurgy, vol. 49, pp. 82-89. 2014.

[4]. Rahman, Amin, Bodhi Febrianto, Crysta Aditya R, and Hendy Tryas Y. 2012. "Rancang Bangun Mesin Pembuat Pupuk Organik Granul Kapasitas $15 \mathrm{Kg} / \mathrm{Jam}$." Politeknik Negeri Semarang. 2012 